\title{
A critical discussion of the physics of wood-water interactions
}

\author{
Emil Tang Engelund • Lisbeth Garbrecht Thygesen • \\ Staffan Svensson - Callum A. S. Hill
}

Received: 2 July 2012/Published online: 14 October 2012

(C) Springer-Verlag Berlin Heidelberg 2012

\begin{abstract}
This paper reviews recent findings on wood-water interaction and puts them into context of established knowledge in the field. Several new findings challenge prevalent theories and are critically discussed in an attempt to advance current knowledge and highlight gaps. The focus of this review is put on water in the broadest concept of wood products, that is, the living tree is not considered. Moreover, the review covers the basic wood-water relation, states and transitions. Secondary effects such as the ability of water to alter physical properties of wood are only discussed in cases where there is an influence on state and/or transition.
\end{abstract}

\section{Introduction}

Wood-water relations have been studied scientifically for at least a century. This implies that at a first glance, the subject appears to be a solved case and no longer interesting or challenging. However, that wood-water relations have been studied

E. T. Engelund $(\square)$

Wood Technology, Danish Technological Institute, Gregersensvej 4,

2630 Taastrup, Denmark

e-mail: ete@teknologisk.dk

L. G. Thygesen

Faculty of Science, University of Copenhagen, Rolighedsvej 23,

1958 Frederiksberg C, Denmark

\section{S. Svensson}

Department of Civil Engineering, Technical University of Denmark, Brovej, build. 118, 2800 Kgs. Lyngby, Denmark

C. A. S. Hill

Centre for Wood Science and Technology, Edinburgh Napier University,

Merchiston Campus, 10 Colinton Road, Edinburgh EH10 5DT, Scotland, UK 
for so many years, also implies that some of the established facts or truths are based on what is now considered inadequate or insufficient data, or originates from interpretations based on now outdated ideas or theories. During the last few years, new findings that contradict established dogma or allow new interpretations of existing data have been published. This review paper will with a summarized version of established knowledge (Venkateswaran 1970; Simpson 1980; Skaar 1984) put into context new findings on wood-water interaction. The focus of this review is put on water in the broadest concept of wood products, that is, the living tree is not considered. Moreover, the review covers the basic wood-water relation, states and transitions. Secondary effects such as the ability of water to alter physical properties of wood will only be discussed in cases where there is an influence on state and/or transition. Throughout this review, moisture content (MC) is described by the ratio of mass of moisture to mass of dry wood substance.

\section{Green wood and fibre saturation}

Freshly cut and never-dried wood is also known as "green" wood. In this state, cell walls are water saturated, and in addition, water is found as liquid, liquid-vapour mixture or vapour in cell lumens. The moisture state of green wood is not a unique quantity; it varies between tree species, within the tree, for example, sapwood or heartwood, between seasons (if in a temporal zone) and possibly also with the time of the day. Chiu and Lin (2007) studied the radial variation in moisture content at breast height of 46-year-old red cypress trees. Moisture content values ranged from approximately 100 to $170 \%$, with the lowest values found in the transition between sapwood and heartwood. For softwoods, the moisture content of heartwood is typically considerably lower than for sapwood (Pallardy and Kozlowski 2008). This is not always the case for hardwoods, for which the relation between moisture content in heartwood and sapwood depends on species and may also depend on season (Pallardy and Kozlowski 2008). Further, as reviewed by Berry and Roderick (2005), the stem diameter of living trees may also shrink during the day and swell during the night as a consequence of diurnal variations in bark and/or xylem moisture content superimposed over cambial growth.

Drying reduces the moisture content of green wood, and if continued, the cell walls will reach unsaturated states. The moisture content at the transition point from saturated to unsaturated state is defined as the fibre saturation point (FSP). This concept was introduced by Tiemann (1906) who defined FSP as the moisture content when lumens are empty of all liquid water, cell walls begin to dry and strength begins to increase. There are two documented problems with this definition. Firstly, the three phenomena do normally not occur at the same moisture content as shown by Stamm (1971). Secondly, during drying, liquid water may still be present in lumens as water desorbs from cell walls of other parts of the same sample (Araujo et al. 1992; Hernández and Bizoň 1994; Almeida and Hernández 2006a, b; Hernández and Pontin 2006). Another definition of FSP was proposed by Stone and Scallan (1967) as the moisture content corresponding to "the amount of water contained within the saturated cell wall". This definition is, however, not 
operational as moisture is not necessarily equally distributed within a wood sample, as just mentioned. It is, however, a definition that in theory can be applied at the single cell level or at the cell wall level. For a block of wood, an operational definition of FSP is to use a purely nominal value, for example, the equilibrium moisture content at a matric water potential of $-0.1 \mathrm{MPa}$, corresponding to a relative humidity of $99.93 \%$, as proposed by Hoffmeyer et al. (2011). With this definition, Norway spruce was found to have an FSP of $42 \% \mathrm{MC}$ at $20^{\circ} \mathrm{C}$. This value agrees with values found using solute exclusion (Hill et al. 2005) and pressure membrane combined with measurements of stiffness and shrinkage (Hernández and Bizoň 1994). These methods yield FSP values in the 38.5-42.5\% MC range for different softwood species. There is thus a difference of about $10 \%$ moisture between the FSP around $30 \% \mathrm{MC}$ which is obtained if a change in how strongly a physical property of wood (electrical conductivity, shrinkage, strength properties) depends on the moisture content is used as basis for the definition (Stamm 1929, 1971 ) and the FSP of about $40 \% \mathrm{MC}$ which is obtained if based on the amount of water present in the cell wall at equilibrium conditions close to $100 \% \mathrm{RH}$ (Hernández and Bizoň 1994; Hill et al. 2005; Engelund et al. 2010; Thygesen et al. 2010; Hoffmeyer et al. 2011). This discrepancy raises the question why the last $10 \% \mathrm{MC}$ within the cell wall (i.e., from 30 to $40 \% \mathrm{MC}$ ) do not affect the physical properties of the cell wall as much as the first $30 \% \mathrm{MC}$, while still apparently being present as bound water (Engelund et al. 2010; Thygesen et al. 2010; Hoffmeyer et al. 2011). Perhaps one should think of fibre saturation not as a state reached at a certain moisture content (i.e., a point) but as a gradual transition from the situation where new water molecules entering the cell wall result in breaking of intra- and intermolecular $\mathrm{H}$-bonds in the wood cell polymers (i.e., up to about $30 \% \mathrm{MC}$ ) to the situation (i.e., from about 30 to $40 \% \mathrm{MC}$ ) where new water molecules are accommodated in the cell wall without breaking further cell wall polymer H-bonds.

\section{States of water in wood}

Nakamura et al. (1981) introduced a nomenclature for water held by cellulosic materials such as wood according to which water may be found in three different states: free water, freezing bound water and non-freezing bound water. The concept was further investigated and developed by Berthold et al. (1994, 1996, 1998). Free water is assumed to be capillary water within cell lumens, whereas bound water interacts with the more or less hydrophilic wood polymers. The division of bound water into freezing and non-freezing components has been quantified using Differential Scanning Calorimetry (DSC) (Nakamura et al. 1981; Berthold et al. 1996). Freezing bound water exhibits a phase change between -10 and $-20{ }^{\circ} \mathrm{C}$, whereas non-freezing bound water does not freeze down to $-70{ }^{\circ} \mathrm{C}$ (Berthold et al. 1996). Freezing bound water has therefore been assumed to be less confined by and more loosely bound to the cell wall than non-freezing bound water, for example, as water clusters in line with theoretical considerations of Hartley et al. (1992) and Hartley and Avramidis (1993). However, Berthold et al. (1996) only found freezing bound water in ligno-cellulosic model compounds containing weak or strong acidic 
groups, that is, not in native wood. Also, Low Field Nuclear Magnetic Resonance (LFNMR) relaxometry performed on wood did not reveal any freezing bound water down to $-20{ }^{\circ} \mathrm{C}$ in Norway spruce sapwood for moisture contents close to FSP (Thygesen et al. 2010). But most importantly, Zelinka et al. (2012) recently presented some very interesting results indicating that the DSC peak hitherto interpreted as freezing bound water in cellulosic materials is consistent with homogeneous nucleation of free water. Further, they showed that this DSC peak only occurred for isolated ball-milled cellulose, not for solid wood or milled wood. According to these results, water in wood is better described as either free or nonfreezing bound water. Thus, freezing bound water does not exist in wood. The results of Zelinka et al. (2012) raise the more general question of how to correctly interpret freezing point depression of water in wood. It is well known that dissolved sugars give a slight freezing point depression of free water. More severe freezing point depressions are normally explained as a result of compartmentalization (Petrov and Furo 2009). Cryo-porometry results are, however, confounded with the influence of water situated at void walls as this water freezes at lower temperatures than water in the centre of voids (Hansen et al. 1997, 2005). There is also the aforementioned strong effect of bonding (Berthold et al. 1996; Zelinka et al. 2012) and possibly also an effect of water being 'ordered' close to wood cell wall polymer surfaces (Matthews et al. 2006). For experimental observations, there is further the difficulty of reaching, maintaining and identifying equilibrium states. Clearly, the temperature ramps used in DSC and in other methods are of paramount importance, and the use of (too) high cooling or heating rates may give dubious results (Landry 2005).

If approaching the question of the states of water in wood from the chemical side rather than the physical side, then hydroxyl groups of the wood polymers are the main chemical component in terms of attracting water molecules. Those hydroxyl groups capable of forming hydrogen bonds with water molecules are termed sorption sites (Simpson 1980) along with other polar chemical groups attracting water (Berthold et al. 1996). The most sorption sites are found in the hemicelluloses followed by cellulose and lignin (Christensen and Kelsey 1959). Cellulose is aggregated into wood microfibrils and two-thirds of the hydroxyl groups are bound between and within cellulose chains constituting the microfibril (O'Sullivan 1997). These hydroxyl groups are inaccessible, while hydroxyl groups on the microfibril's surface are possible sorption sites (Maréchal and Chanzy 2000; Hofstetter et al. 2006). The amount of sorption sites in wood can be estimated from the molecular mass of wood components and the number of sorption sites they contain. Since hydroxyl groups are the primary sorption sites, the concentration of these can be used as an estimate of the amount of sorption sites present in the various wood polymers as shown in Table 1. As hydroxyl groups made inaccessible through binding between polymers or steric hindrance are not considered, this estimate expresses a theoretical upper limit. Since two-thirds of the hydroxyl groups of cellulose are known to be inaccessible to water, a more correct estimate of the amount of sorption sites in cellulose is $6.1 \mathrm{mmol} / \mathrm{g}$. This value is smaller than the hydroxyl concentration of the various lignin models shown in Table 1 and suggests that the actual amount of water accessible sorption sites in lignin is lower. Based on 
Table 1 Concentration of hydroxyl groups in various wood polymers

\begin{tabular}{lllll}
\hline Wood polymer & Formula unit & $\begin{array}{l}\text { Molecular mass } \\
{[\mathrm{g} / \mathrm{mol}]}\end{array}$ & OH-groups & $\begin{array}{l}\text { OH concentration } \\
{[\mathrm{mmol} / \mathrm{g}]}\end{array}$ \\
\hline Cellulose & $\mathrm{C}_{12} \mathrm{O}_{10} \mathrm{H}_{20}$ & 324 & $6^{\mathrm{f}}$ & $18.5^{\mathrm{f}}$ \\
Xylan $^{\mathrm{a}}$ & $\mathrm{C}_{33} \mathrm{O}_{24} \mathrm{H}_{52}$ & 833 & 12 & 14.4 \\
Glucomannan $^{\mathrm{b}}$ & $\mathrm{C}_{30} \mathrm{O}_{24} \mathrm{H}_{44} \mathrm{R}_{6}{ }^{\mathrm{g}}$ & $795-1,049$ & $9-15$ & $8.6-18.8$ \\
Lignin $^{\mathrm{c}}$ & $\mathrm{C}_{160} \mathrm{O}_{58} \mathrm{H}_{178}$ & 3,029 & 24 & 7.9 \\
Lignin $^{\mathrm{d}}$ & $\mathrm{C}_{278} \mathrm{O}_{96} \mathrm{H}_{300}$ & 5,177 & 39 & 7.5 \\
Lignin $^{\mathrm{e}}$ & $\mathrm{C}_{301} \mathrm{O}_{110} \mathrm{H}_{335}$ & 5,713 & 45 & 7.9 \\
\hline
\end{tabular}

Formula units derived from wood-polymer models from (a) to (b) (Sjöström 1993), (c) (Adler 1977), (d) (Sakakibara 1980) and (e) (Reid 1995)

f only $33 \%$ of the cellulose $\mathrm{OH}$-groups are accessible to water. This gives a water accessible $\mathrm{OH}$ concentration of in situ cellulose of $6.1 \mathrm{mmol} / \mathrm{g}$

${ }^{\mathrm{g}} \mathrm{R}=\mathrm{CH}_{3} \mathrm{CO}$ or $\mathrm{H}$

the composition of the various softwood species given in Kollmann and Côté (1968) and assuming a xylan-glucomannan distribution of 2:1 (Sjöström 1993), the amount of sorption sites in softwood is found in the range $8.4-8.9 \mathrm{mmol} / \mathrm{g}$ with an average of $8.6 \mathrm{mmol} / \mathrm{g}$. This latter value is similar to that calculated by Hill and Jones (1999) using the same approach. At FSP of $40 \%$ MC this corresponds with 2.6 water molecules per hydroxyl group on average. An experimental indication of the amount of sorption sites is given by Hill and Jones (1999) who modified Corsican pine with different-sized linear chain anhydrides. They found a second-order relationship between molar volume of anhydrides and amount of substituted hydroxyl groups. By extrapolation, the amount of sorption sites in wood was found to be $5.7( \pm 0.4) \mathrm{mmol} / \mathrm{g}$, that is, significantly lower than the theoretical estimates. This value corresponds with an average of 3.9 water molecules per hydroxyl group at FSP. However, independent means of verification of the amount of sorption sites was deemed necessary (Hill and Jones 1999).

Bergenstråhle et al. (2008) compared CP/MAS ${ }^{13} \mathrm{C}$ NMR results to molecular dynamics simulations of aggregates of cellulose crystals and found that water molecules bound to two different crystallographic planes of the cellulose aggregates had different spin-lattice relaxation times, indicating a difference in bonding between these two accessible sides of the aggregates. Estimates of the average number of water molecules per sorption site (Berthold et al. 1996; Joly et al. 1996) indicate that typically only 1-2 water molecules attach to each sorption site. At low moisture content, it is suggested that water molecules may bind to two neighbouring hydroxyl groups simultaneously (Joly et al. 1996). As mentioned above, no water is present within cellulose crystals, so if water molecules are bound to two sorption sites on cellulose, this has to take place on the accessible surfaces of cellulose aggregates or between neighbouring aggregates. This also implies that calculations of the average number of water molecules per sorption site in wood cell wall polymers do not express anything about the actual distribution of water molecules between sorption sites, unless only accessible sites are included in the estimation. 
A number of studies have employed different variants of LFNMR relaxation experiments in an attempt to identify the states of water present in wood and other ligno-cellulosic materials. A small overview of LFNMR studies employing CarrPurcell-Meiboom-Gill (CPMG) measurements for the identification of wood-water states was given by Thygesen and Elder (2008). In summary, CPMG finds only two states of water: lumen water and wood cell wall water. According to Araujo et al. (1994), cell wall water diffuses so fast that chemical exchange between different bonding states (if they exist) evens out any differences in relaxation times and results in a single population being found for cell wall water. Employing a more advanced $2 \mathrm{D} \mathrm{T}_{1}-\mathrm{T}_{2}$ LFNMR experiment, Cox et al. (2010) were able to identify two different states of water within the wood cell wall. These two components had similar spin-spin relaxation times (thus resulting in only one CPMG population), but different spin-lattice relaxation times. The two components were tentatively assigned to 'mobile water and possibly water in small voids', respectively, to 'less mobile water that swells wood polymers'. In the light of the recent results by Zelinka et al. (2012), these two states of water cannot be interpreted as freezing and non-freezing bound water, respectively. Perhaps the two types of water found by Cox et al. (2010) correspond to water bound to the two different accessible sides of cellulosic microfibrils identified by Bergenstråhle et al. (2008), as these were also found to have different spin-lattice relaxation times. However, that water bound to two different sides of cellulose aggregates should be separable while water bound to hemicelluloses or lignin should blend into these two populations and not stand out does on the other hand seem peculiar.

\section{Sorption isotherm}

Being hygroscopic, wood will constantly exchange moisture with the ambient air. An equilibrium moisture state of wood is attained when there is no measurable exchange of moisture between a volume of wood and its surroundings. For wood used under real-life conditions, it is doubtful whether equilibrium is ever attained because of the often very long time it takes to reach equilibrium at given conditions and due to the typically varying nature of the surrounding conditions, for example, varying air humidity. A sorption isotherm is a discrete representation of equilibrium moisture states of wood with its surrounding environment attained in constant temperature and water vapour pressure (or relative humidity, $\mathrm{RH}$ ) in the hygroscopic range. Each equilibrium moisture state of wood illustrated in the sorption isotherm is reached after either uptake (adsorption) or release (desorption) of water molecules; both processes with significant duration (Fig. 1). These processes are thermodynamically complex and involve both a change in temperature, see Figs. 1 and 2, and volume, that is, both heat and work are involved in the process of attaining the equilibrium moisture state. The sorption isotherm of wood has a sigmoid shape. This so-called type II sorption isotherm is characteristic for gas-solid solution sorption of deformable solids and for a sorption process accompanied with significant heat of sorption (Brunauer 1943). 

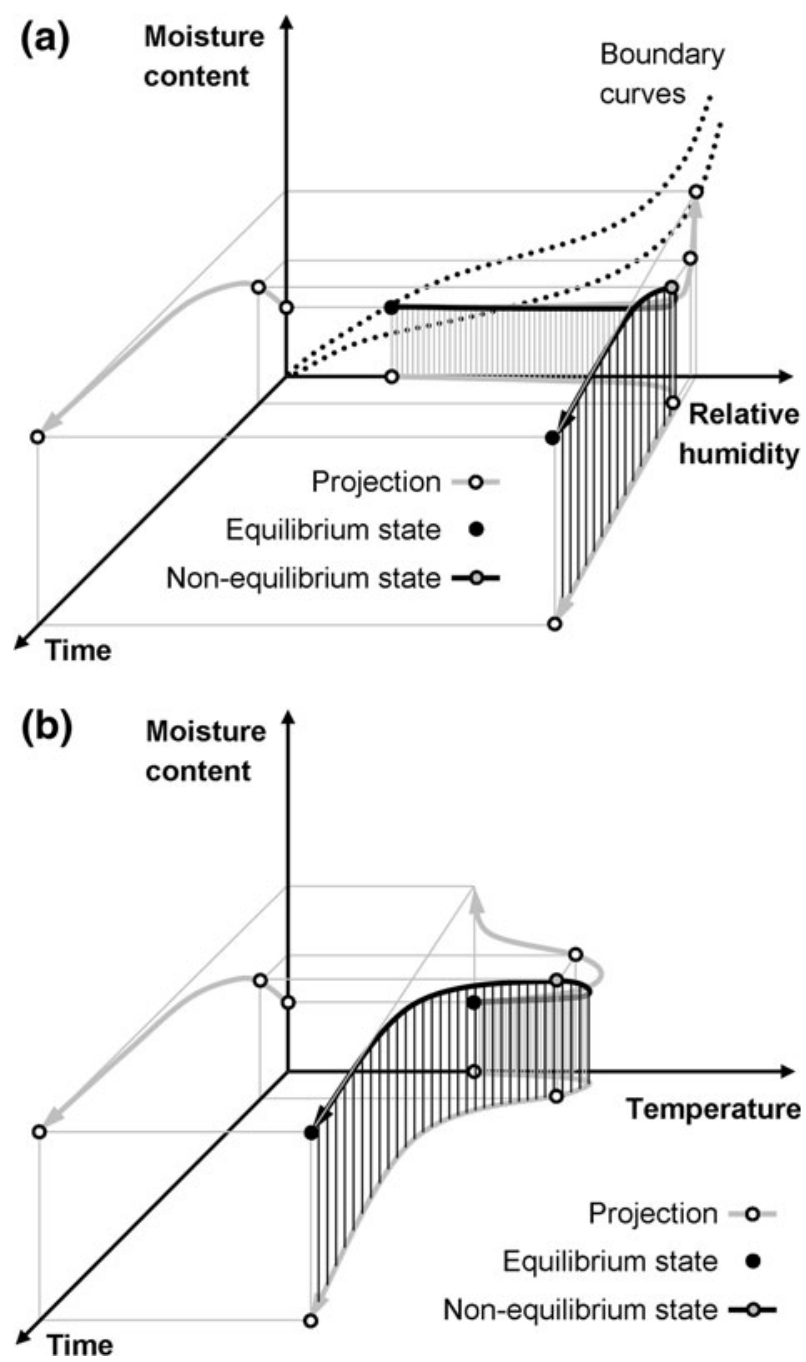

Fig. 1 Schematic illustration of an adsorption process depicted in three-dimensional a moisture contentrelative humidity-time domain, and $\mathbf{b}$ moisture content-temperature-time domain. The process is projected on the moisture content-relative humidity plane along with sorption boundary curves, on the relative humidity-time plane, on the moisture content-temperature plane, on the temperature-time plane and on the moisture content-time plane. Concept adapted from Frandsen (2007)

Temperature level influences the equilibrium moisture state. Increased temperature level decreases the equilibrium moisture content of wood for a given constant vapour pressure. For temperatures of $75{ }^{\circ} \mathrm{C}$ and above, a unique relation between equilibrium moisture content of the wood and (relative) vapour pressure of ambient air exists (Weichert 1963). At lower temperatures, the relation between equilibrium moisture content and vapour pressure is hysteric and enveloped by the two extremes: adsorption isotherm and desorption isotherm (e.g. Seborg and Stamm 
Fig. 2 Schematic illustration of adsorption and desorption processes of wood in a vacuum apparatus between 3.0 and $9.8 \%$ MC plotted in the moisture content-temperature plane, based on moisturetemperature data for small specimens of White oak taken from Kelly and Hart (1970)

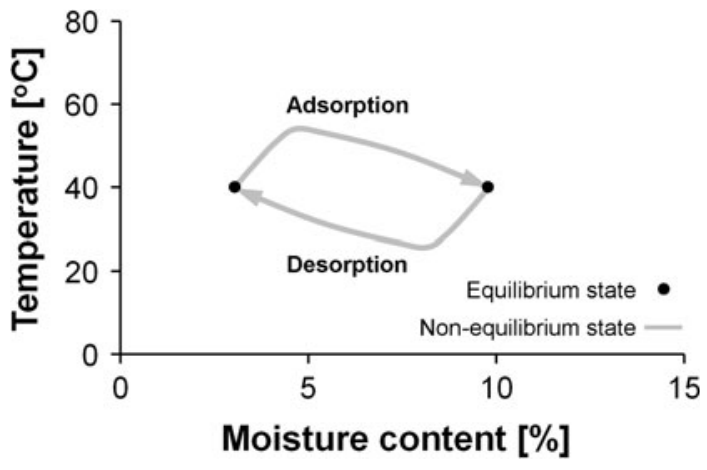

1931; Stamm and Woodruff 1941; Kelsey 1957). If desorption takes place from FSP, then the desorption branch describes what is known as a boundary curve. If desorption takes place from any lower moisture content than FSP, the desorption path follows a scanning curve which crosses the region enclosed by the two (adsorption and desorption) boundary curves.

As mentioned above, recent results indicate that below FSP, non-freezing bound water constitutes the only state of water present. By measuring the sorption enthalpy related to the adsorption of water molecules to amorphous cellulose, Joly et al. (1996) found that up to $40-50 \% \mathrm{RH}$, the sorption enthalpy was constant and corresponded to binding of one water molecule per glucose unit. A similar observation was made by Fringant et al. (1996) on various other polysaccharides. In both studies, the sorption enthalpy decreased between 50 and $85 \% \mathrm{RH}$ as water uptake increased from 1 to 2 water molecules per glucose unit. Joly et al. (1996) suggest that at moisture contents corresponding to one water molecule per glucose unit or less, the water can be bound energetically more favourable to two neighbouring sorption sites. This is supported by spectroscopic and computational results on water-monosaccharide interactions by Çarçabal et al. (2005) which show ordering of hydrogen bonds within the monosaccharides by attaching one water molecule.

Around $60-70 \% \mathrm{RH}$, the sorption isotherm of wood exhibits an upward bend, that is, an increase in the first derivative $\mathrm{dRH} / \mathrm{dMC}$, which traditionally has been attributed to sorption of free water in capillaries (Sheppard 1933; Barkas 1937; Babbitt 1942; Stamm 1950; Spalt 1958; Kollmann 1962), at least above $90 \%$ RH. Thygesen et al. (2010) investigated the sorption behaviour in the range 90-99.9\% $\mathrm{RH}$ of both unmodified wood and acetylated wood where a fraction of the sorption sites had been chemically replaced. From comparison of the results of these two and from supportive evidence from LF-NMR, it was concluded that sorption of capillary water is insignificant below $99.5 \% \mathrm{RH}$. This conclusion was further elaborated by theoretical calculations (Engelund et al. 2010). Thus, the upward bend of the sorption isotherm does not seem to be due to capillary sorption.

Another explanation for the upward bend of the sorption isotherm is related to softening of amorphous polymers (Mauze and Stern 1984; Vrentas and Vrentas 1991). Softening is the transition from a glassy to rubbery state of amorphous 
Fig. 3 a Softening of hemicelluloses (circles) and lignin (triangles) as a function of wood moisture content. Experimental data from Becker and Noack (1968), Irvine (1984), Kelley et al. (1987), Olsson and Salmén (2004), Stevens et al. (1983). Grey lines mark isohumes, that is, lines of constant $\mathrm{RH}$, derived from the standard softwood sorption isotherm (Forest Products Laboratory 2010), adapted from (Engelund 2011). b Standard softwood sorption isotherm (Forest Products Laboratory 2010) at three temperature levels indicating region of woodpolymer softening. The two states marked by points A and B are the same in both diagrams

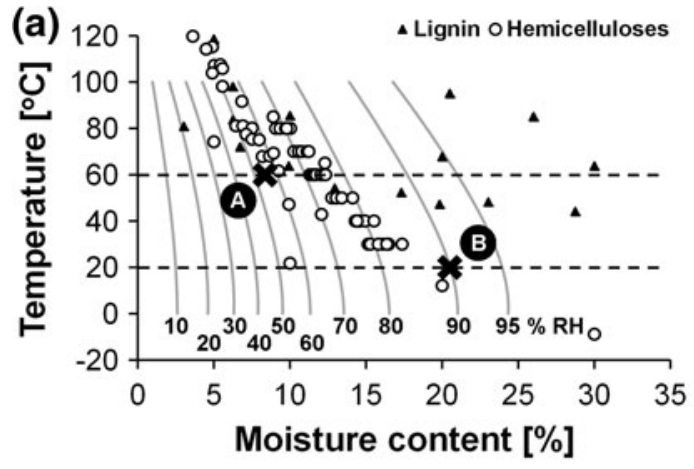

(b)

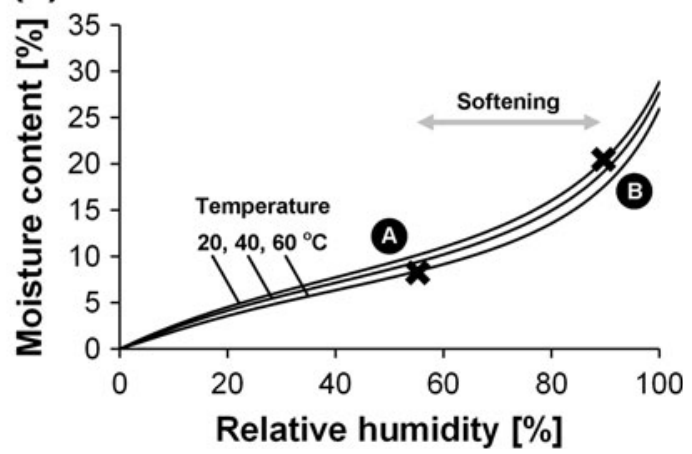

polymers which significantly decreases the viscosity and rigidity of the polymeric network. This might increase the capacity to accommodate water molecules in the cell wall. At room temperature, softening of hemicelluloses occurs around $75 \% \mathrm{RH}$ (Olsson and Salmén 2004). It depends, however, both on temperature and moisture content of the wood as illustrated in Fig. 3. This clearly shows that the softening curve for hemicelluloses crosses the isohumes, that is, lines of constant $\mathrm{RH}$, in the region 60-90\% $\mathrm{RH}$ at room temperature.

A fair amount of models have been proposed for sorption isotherms with sigmoid shape. According to Skaar (1988), 77 mathematical equations predicting the sorption isotherms of different biological materials including wood are listed in Van den Berg and Bruin (1981), of which many were found by Boquet et al. (1980) to be mathematically equivalent. Many of them coincided with the second-degree polynomial expression first presented by Hailwood and Horrobin (1946). Excluding the empirical models, two approaches to describe type II sorption among the proposed models are found. One approach considers sorption to be a surface phenomenon while the other considers it as a solution phenomenon. The most known model of the previous type is the BET sorption theory (Brunauer et al. 1938). The modification of the BET model into the Dent (1977) sorption model makes it adequate for the whole hygroscopic range. A drawback of both BET and Dent models is, however, the inconsistency with the thermodynamic aspects of sorption. 
Furthermore, the mathematical expression of the Dent model is identical to that first presented by Hailwood and Horrobin (1946). The Hailwood and Horrobin model is based on the second approach, that is, sorption seen as a solution phenomenon, and considers different grades of hydrated wood, dry wood and dissolved water as an ideal solution. Although this model out of ten selected models gave the best fit to experimental data in an evaluation by Simpson (1973), the Hailwood and Horrobin model, like the Dent model, is not able to accurately account for heat of sorption and other accompanying quantities. In general, all wood sorption models and modifications of them found in literature have, even though they might fit experimental data adequately, obvious flaws usually in relation to thermodynamics (Simpson 1980). One or more assumptions made when deriving the models are in most cases questionable since significant parts of the complex process of attaining equilibrium moisture state are not considered. Also, and perhaps more seriously, the reliability of the experimental data used when deriving and/or verifying the different models is questionable. The sensitivity of the seemingly simple test, of measuring the mass difference of a wood specimen at two different equilibrium moisture states attained in a thermodynamic system where temperature is kept constant and where there is a uniform step change between two levels of non-fluctuating humidity, has been and still is apparently underestimated.

\section{Hygro-expansion and sorption hysteresis}

In the dry state, voids and pores are essentially absent from the wood cell wall (Griffin 1977; Fahlén and Salmén 2005; Salmén and Fahlén 2006). When water enters the cell wall, it therefore causes swelling of the material, occupying space between the microfibrils and thereby forcing them apart. Furthermore, the microfibrils themselves experience a change in dimensions (Abe and Yamamoto 2005, 2006; Zabler et al. 2010; Toba et al. 2012). Swelling also results in increased cell wall dimensions. The macroscopic swelling of wood in the tangential direction has been found to be directly proportional to swelling at the cell wall level (Murata and Masuda 2006). On this level, the swelling of latewood in the transverse directions is similar (Murata and Masuda 2006; Derome et al. 2011). For earlywood, however, the swelling in the tangential direction is similar to that of latewood, whereas the swelling in the radial direction is significantly lower (Derome et al. 2011). This may be caused by rays, which are oriented in the radial direction, restraining swelling of the thin-walled earlywood cells more than swelling of the stiffer, thick-walled latewood cells (Ma and Rudolph 2006; Derome et al. 2011). On the macroscopic scale, swelling in the two transverse directions also differs in that tangential swelling is greater than radial swelling. Swelling in the longitudinal direction of softwood is for normal wood significantly lower (Hunt and Shelton 1988; Derome et al. 2011) than in transverse directions because the microfibrils are aligned more or less in the longitudinal direction of the wood. In the range 5-20\% moisture content, the relation is linear between swelling of wood and amount of moisture both on macroscale (Stamm 1959; Hartley and Avramidis 1996) and microscale (Ma and Rudolph 2006; Murata and Masuda 2006). 
As mentioned previously, no unique relation exists between ambient climate and moisture content in softwood at temperatures below $75{ }^{\circ} \mathrm{C}$ (Weichert 1963). Below this temperature, the difference between equilibrium moisture content reached by adsorption from the dry state and desorption from saturation increases with decreasing temperature (Djolani 1972; Hill et al. 2010). This dependence on moisture history is termed sorption hysteresis. One special aspect of this is the desorption from green condition which often is regarded as distinct from any subsequent desorption from saturated condition. The experimental results of Spalt (1958) are often quoted to support the notion that the equilibrium moisture content at certain climatic conditions above $70 \% \mathrm{RH}$ is significantly higher than for any later desorption from saturation. Hoffmeyer et al. (2011) have, however, recently shown that drying in vacuum over a desiccant and subsequent vacuum saturation in liquid water results in almost complete reproducibility of the first desorption isotherm. Small differences between desorption isotherms dependent on drying and preparation procedure were seen, nonetheless. Sorption hysteresis is widely encountered when sorption properties of microporous materials are studied (Rouquerol et al. 1999). Various theories have been advanced to explain the phenomenon. One such is the "ink bottle" theory which explains the phenomenon by suggesting a stable quasi-equilibrium during desorption between the surface meniscus of water at the throat of nanopores with much smaller diameter than the characteristic pore diameter. Another theory considers the differences between adsorption and desorption loops as due to changes in contact angle between sorbed water and the internal surface of the wood material (Chen and Wangaard 1968). Both of these theories assume the presence of liquid water, that is, capillary water, which is not significantly present below $99.5 \% \mathrm{RH}$ as discussed above.

Other theories along with mathematical models have been published offering explanations to sorption hysteresis. One such is independent domain theory (Everett 1955) which has been applied to wood by Peralta $(1995,1996)$. The physical interpretation of the parameters involved is, however, not straightforward. A review of some of the existing models for describing sorption hysteresis is given in Frandsen et al. (2007). In general, no physically consistent model for sorption hysteresis has been put forward.

The physical explanation for sorption hysteresis in swelling media such as wood might be related to the process of hygro-expansion. The structure and composition of wood cell wall material can be seen as a very complex, heterogeneous gel type. The layered structure with long cellulose chains almost inert in their length direction is a formidable constraint to any form of hygro-expansion/contraction. Barkas (1949) makes the analogy between constrained swelling of a gel and reverse osmosis. The hydrostatic tension/pressure established by the restraint of shrinking/ swelling of the gel will alter the equilibrium moisture state in the same way as pressure on the solution in reverse osmosis will alter its equilibrium concentration. Contrary to the large stiffness in the length direction of the cellulose chains, the rigidity of the layered structure of the cell wall is relatively agile, that is, it allows deformation. The deformation is in several publications described as slippage between the microfibrils (Balashov et al. 1957; Olsson and Salmén 2004; Engelund and Svensson 2011). This slippage is facilitated by breaking and re-bonding of 
hydrogen bonds (Grossman 1976), a process that makes the deformations timedependent (Hunt and Gril 1996; Hanhijärvi and Hunt 1998) and assures stress relaxation. Even though Barkas did not consider time-dependent behaviour, the analogy still holds. This means that the equilibrium moisture state of wood will change along with stress state which depends on the rate of stress relaxation. Hence, the equilibrium moisture state will change during a sorption process also after the step change when the ambient vapour pressure is held constant. The interdependence between moisture state and stress state is also seen when external loads are applied (Olsson and Salmén 2001).

Adding to the complexity is the possibility that one or more of the constitutive materials will pass their glass transition during sorption from one equilibrium state to another, as shown in Fig. 3. As a result of the transition, a material will drastically change mechanical characteristics from those of a solid below the glass transition temperature to those of a fluid above. A transition will have a significant effect on the stress relaxation and therefore on the equilibrium moisture state of the wood material. Thus, the disappearance of sorption hysteresis above $75{ }^{\circ} \mathrm{C}$ could be due to softening of hemicelluloses discussed previously. The effect on the timedependent relaxation is addressed by Vrentas and Vrentas (1996) as key to sorption hysteresis. As the material or part hereof enters the glassy state, the volumetric relaxation following hygro-expansion/contraction is significantly slowed down, hereby locking or "freezing" an amount of free volume in the polymeric material. This results in a difference in swollen volume at similar moisture content dependent on the moisture history. Experimental results for wood (Djolani 1972; Seifert 1972; Hernández 1993; Hartley and Avramidis 1996; Arevalo and Hernández 2001; Chauhan and Aggarwal 2004) in fact indicate a small difference in swollen volume in a volume versus moisture content plot. Some of these ideas have been applied to sorption hysteresis in wood (Hill et al. 2010). Furthermore, it has been suggested that the sorption kinetics displayed at the cell wall level can be linked to hysteresis by considering the process of polymer relaxation in the inter-microfibrillar matrix (Hill et al. 2012).

\section{Moisture transport}

Transport of water in an open porous hygroscopic material such as wood is a complex mass transfer with fully coupled processes of water in different phases (Babbitt 1950). In the porous system, three phases of water are possible: solid (ice), liquid and gas (vapour). With the exception of capillary suction when wood is partly submerged in or in direct contact with liquid water, transport of moisture within the porous system is strongly connected to vapour diffusion. Although transport of liquid water as capillary flow may be significant in cases of long unbroken capillaries, the phenomenon is of little relevance except for water transport in living trees or for drying of sawn lumber. In the hygroscopic moisture range, characteristic for all seasoned wood material in natural climate without direct contact to liquid water, vapour alone is present in the porous system of wood. For this most common 


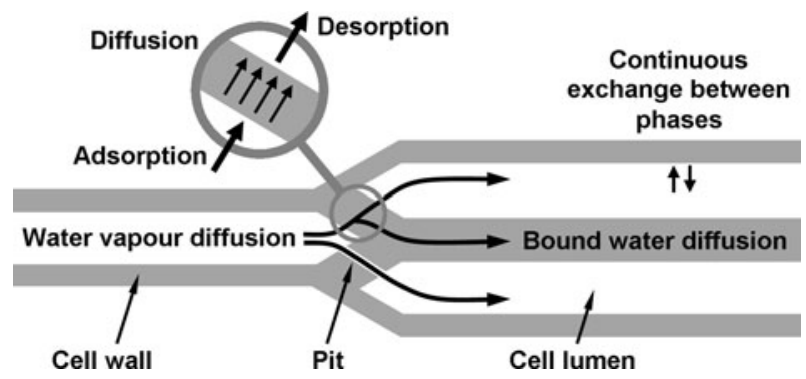

Fig. 4 Schematic illustration of moisture transport in softwood below FSP in the longitudinal direction of the xylem, based on Krabbenhøft and Damkilde (2004)

case, moisture transport is governed by three processes (Stamm 1960): diffusion of vapour in the porous system, sorption, and diffusion of bound water in the wood cell wall, see Fig. 4. Each of the two diffusion processes can be mathematically described by a Fickian equation, and they are coupled by a sorption term (Gamstedt et al. 2012).

Diffusion of vapour in the porous system is controlled both by the properties of the medium itself as well as the resistance from the porous structure (Krabbenhøft and Damkilde 2004) from, for example, longer path lengths through the lumens and other cavities in wood. Diffusion of vapour in air decreases with increasing vapour pressure (Schirmer 1938) due to shorter mean free path of the water molecules. The diffusion characteristics of bound water in cell walls are difficult to determine experimentally. This is mainly because of the very slow diffusion of bound water compared to vapour diffusion in the porous structure. Thus, for moisture transport in larger wood specimens, bound water transport is of little significance (Hozjan and Svensson 2011). The simplest method for evaluating diffusion characteristics is perhaps the cup method where steady-state transport of water through a material specimen is measured. Accurate derivation of diffusion characteristic of a single phase, for example, the bound water phase can, however, only be achieved if the transport is limited to that single phase. An indication of characteristics such as the diffusion coefficient of bound water in wood may, however, come from permeability measurements on thin films of wooden polymers. Péroval et al. (2002) used the cup method to determine water transport through arabinoxylan films. Correcting their results for resistance from still air inside the cup based on Hansen and Lund (1990) yields a diffusion coefficient of arabinoxylan films of about $1 \times 10^{-12} \mathrm{~m}^{2} / \mathrm{s}$. Similar results in the range $0.1 \times 10^{-12}-7 \times 10^{-12} \mathrm{~m}^{2} / \mathrm{s}$ were found by Stamm (1956) on uncoated cellophane films. No correction is needed for these results, since air circulation was ensured both inside and outside the cup. The diffusion coefficient for bound water diffusion in wood cell walls is presumably of the same order of magnitude as that found for cellophane and hemicelluloses films. The results show that the diffusion coefficient increases exponentially with increasing moisture content, a trend which is also seen for larger wood specimens (Comstock 1963). 


\section{Rate of sorption}

Sorption of water in wood is the process of uptake (adsorption) or release (desorption) of bound water in cell walls in the local approach to equilibrium between the concentration of bound water and the concentration of water vapour in adjacent macrocavities. On larger wood specimens, the rate of sorption may also depend on the rate of diffusion of both water vapour and bound water between the macroscopic surface and the core of the specimen. The focus of this section is, however, put on the rate of sorption of cell walls themselves. In order to investigate this and separate sorption from diffusion of water vapour, very thin wood samples must be used which was done in a range of sorption experiments by Christensen (1959, 1965, 1967), Christensen and Kelsey (1959) and Kelly and Hart (1970) using a vacuum apparatus.

As described for moisture transport in wood, the diffusion of bound water in the cell wall can be described by a Fickian equation. It is therefore natural to assume that sorption might be controlled by diffusion between the lumen-cell wall interface and the interior of the cell wall. This is assumed by Kelly and Hart (1970) who found values for the bound water diffusion coefficient of magnitude $10^{-14} \mathrm{~m}^{2} / \mathrm{s}$, that is, about two orders of magnitude lower than the value for hemicellulose and cellophane films described previously. It should be noted, however, that during sorption in the vacuum apparatus employed by Kelly and Hart (1970), the temperature changes significantly as can be seen in Fig. 2. The transport of bound water in these non-isothermal conditions is therefore also influenced by a thermal gradient, which is not accounted for by using concentration as the single driving potential in the Fickian model. Nonetheless, a somewhat slower diffusion into the cell walls is expected because of the change in temperature at the interface as suggested by Kelly and Hart (1970) and Eitelberger et al. (2011). During adsorption, the temperature increases at the interface because of positive sorption enthalpy. This will raise the activity of bound water at the interface and thus lower the local driving potential, that is, the gradient in activity between water vapour and interface bound water. On the other hand, the increased activity of interface bound water results in a greater activity gradient inside the cell wall and aids the diffusion from the interface into the cell wall. During desorption, these effects are reversed. Substantial temperature changes may especially occur when employing vacuum equipment as illustrated by the results of Christensen and Kelsey (1959) shown in Fig. 5, in particular for low initial moisture contents. In the presence of air, temperature changes during sorption are less extreme. As illustrated in Fig. 5, the temperature increase during adsorption is lower, the larger the initial moisture content becomes. This reflects both an increase in heat capacity which increases by $50 \%$ between 0 and $15 \%$ MC (Sonderegger et al. 2011) and a decrease in sorption enthalpy (Joly et al. 1996; Fringant et al. 1996), as well as larger thermal conductivity and a slower process of adsorption at higher moisture contents.

In a series of experiments in vacuum, Christensen $(1959,1965)$ observed that time to equilibrium increased with increasing initial moisture content for similar steps in RH. A similar decrease in sorption rate with increasing initial moisture content is found for water sorption by thin films of hemicelluloses (Sadoh and 
Fig. 5 Schematic illustration of successive adsorption processes in a vacuum apparatus from 0 to $22.5 \%$ MC plotted on top of the moisture content-temperature plane from Fig. 3a, based on moisture-temperature data for small specimens of Klinki pine taken from Christensen and Kelsey (1959)

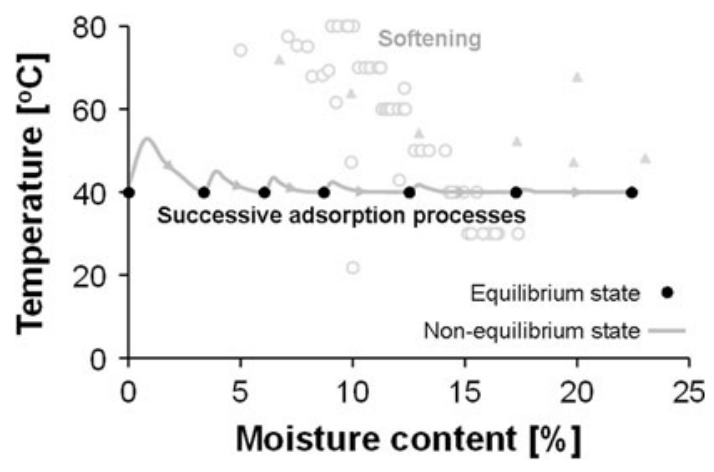

Christensen 1964). However, the diffusion coefficient is known to increase with increasing initial moisture content and should thus facilitate a faster approach to equilibrium. Furthermore, the approach to equilibrium seems independent of the thickness of the wood cell walls from comparison of sorption results for balsa $(1 \mu \mathrm{m})$ and satin box wood $(4 \mu \mathrm{m})$ (Christensen 1965). These results indicate that sorption is not controlled by diffusion.

Another candidate for the controlling factor of sorption is the relaxation of swelling and/or thermal stresses caused by local changes in concentration of bound water and/or temperature (Christensen 1959; Sadoh and Christensen 1964). This is in line with the concepts by Crank (1953) who explained non-Fickian sorption in polymers as a relaxation of shear stresses. Crank (1953) suggests, however, that these stresses in polymers are a result of concentration gradients, that is, gradients in swelling pressure. In wood cell walls, the restraining effect of cellulose microfibrils on the swelling amorphous polymers, hemicelluloses and lignin, might cause significant stress gradients without large gradients in bound water concentration being present. Time-dependent behaviour of wood cell walls has been ascribed to shearing in the material directions (Balashov et al. 1957; Lotfy et al. 1972; Olsson and Salmén 2001; Engelund and Svensson 2011). The rate of sorption should therefore be related to the rate of relaxation of shear swelling stresses in wood cell walls. In fact, Newns (1956) utilizes an expression for swelling over time as a function of swelling pressure which is of similar form as that expression used to describe creep in wood by Engelund and Svensson (2011).

In adsorption experiments, Christensen and Hergt (1969) observed a slower rate of adsorption and longer time to equilibrium the longer samples were conditioned at $53 \% \mathrm{RH}$ prior to the initiation of sorption. Furthermore, Christensen (1959) and Christensen and Kelsey (1959) found that the halftime to equilibrium was inversely proportional to swelling pressure, that is, smaller steps in $\mathrm{RH}$ gave a longer time to equilibrium. These observations indicate that greater swelling stresses could be generated in the cell wall, the less stress relaxation had occurred at the previous $\mathrm{RH}$ level. As stress relaxation progresses, the sorptive capacity of the cell wall increases, hereby facilitating more bound water to be adsorbed. This might even be true at the interface between water vapour and bound water. Hereby, equilibrium in the outermost part of the cell wall is not instantaneous but changes gradually after a change in water vapour pressure. Such behaviour has been observed for adsorption 
of iodohexane in polystyrene films (Hui et al. 1987) and adsorption of methyl iodide in cellulose acetate films (Long and Richman 1960), where the surface concentration of adsorbate was time-dependent. Thus, as stress relaxation progresses, the equilibrium surface concentration changes.

Several researchers have described sorption of water in the cell walls by a twostage process (Christensen 1965; Christensen and Hergt 1969; Xie et al. 2011; Hill et al. 2012) for which moisture uptake in the initial stage resembles a process controlled by Fickian diffusion. The second stage is slower and becomes increasingly dominant as the initial concentration of bound water is increased (Christensen 1965). It is most pronounced above 40-50 \% RH (Christensen 1965) where stress relaxation proceeds faster due to greater mobility of the amorphous wood polymers above glass transition. A similar behaviour has been reported for other swelling polymeric substances such as wool (Downes and Mackay 1958), hemicelluloses (Sadoh and Christensen 1964) and cellulose acetate (Bagley and Long 1955; Newns 1956). Hill and co-workers (Xie et al. 2011; Hill et al. 2012) have shown that from a mathematical standpoint, sorption kinetics can be modelled as a sum of two exponential decays: a relatively fast and a relatively slow process. Although it is argued in this work that sorption is controlled by relaxation, the apparent two-stage nature of sorption remains to be explained.

\section{Conclusion}

During the last couple of years, a number of axioms within wood-water relations have been challenged, and new results and ideas have emerged:

1. New results based on DSC and LFNMR indicate that only two kinds of water are present in native wood: free water in the porous system (cell lumens etc.) and non-freezing bound water inside the cell walls. All of the bound water molecules are suggested to be bound directly to one or two sorption sites, mainly hydroxyl groups.

2. Below fibre saturation, that is, throughout the hygroscopic range, capillary sorption does not in any significant extent take place in native wood.

3. The upward bend of the sorption isotherm of wood above approximately $70 \%$ $\mathrm{RH}$ is most likely due to softening of hemicelluloses, which at room temperature crosses the glass transition point at this moisture range and thus allows accommodation of more water molecules within the wood cell wall.

4. Sorption hysteresis is presumably also linked to the glass transition of hemicelluloses, where volumetric relaxation processes following hygroexpansion/contraction are suggested to be governed by the moisture contentdependent mobility of the hemicelluloses component of the wood cell wall.

5. Considerable progress has been made regarding the understanding and modelling of moisture transport processes in wood.

6. Regarding the rate of sorption, it has been realized that stress relaxation plays a dominant role, while diffusion processes are less important. 
Acknowledgments This review is based on the development of fundamental knowledge within the network of COST Action FP0802 "Experimental and computational micro-characterization techniques in wood mechanics" during the years 2008-2012. The authors are grateful to the support from the European Science Foundation through COST and to all scientists contributing to the development work in this network.

\section{References}

Abe K, Yamamoto H (2005) Mechanical interaction between cellulose microfibril and matrix substance in wood cell wall determined by X-ray diffraction. J Wood Sci 51:334-338

Abe K, Yamamoto H (2006) Behavior of the cellulose microfibril in shrinking woods. J Wood Sci 52:15-19

Adler E (1977) Lignin chemistry-past, present and future. Wood Sci Technol 11:169-218

Almeida G, Hernández RE (2006a) Changes in the physical properties of tropical and temperate hardwoods below and above the fiber saturation point. Wood Sci Technol 40:599-613

Almeida G, Hernández RE (2006b) Changes in the physical properties of yellow birch below and above the fiber saturation point. Wood Fiber Sci 38:74-83

Araujo CD, MacKay AL, Hailey JRT, Whittall KP, Le H (1992) Proton magnetic resonance techniques for characterization of water in wood-application to white spruce. Wood Sci Technol 26:101-113

Araujo CD, Avramidis S, MacKay AL (1994) Behavior of solid wood and bound water as a function of moisture content-a proton magnetic resonance study. Holzforschung 48:69-74

Arevalo R, Hernández RE (2001) Influence of moisture sorption on swelling of mahogany (Swietenia macrophylla King) wood. Holzforschung 55:590-594

Babbitt JD (1942) On the adsorption of water vapour by cellulose. Can J Res A 20:143-172

Babbitt JD (1950) On the differential equations of diffusion. Can J Res A 28:449-474

Bagley E, Long FA (1955) Two-stage sorption and desorption of organic vapors in cellulose acetate. J Am Chem Soc 77:2172-2178

Balashov V, Preston RD, Ripley GW, Spark LC (1957) Structure and mechanical properties of vegetable fibres-1. The influence of strain on the orientation of cellulose microfibrils in sisal leaf fibre. Proc R Soc Lond B Biol 146:460-468

Barkas WW (1937) Wood-water relationships-part 3. Molecular sorption of water by sitka spruce wood. Proc Phys Soc 49:237-242

Barkas WW (1949) The swelling of wood under stress. HM Stationary Office, London

Becker H, Noack D (1968) Studies on dynamic torsional viscoelasticity of wood. Wood Sci Technol 2:213-230

Bergenstråhle M, Wohlert J, Larsson PT, Mazeau K, Berglund LA (2008) Dynamics of cellulose-water interfaces: NMR spin-lattice relaxation times calculated from atomistic computer simulations. J Phys Chem B 112:2590-2595

Berry SL, Roderick ML (2005) Plant-water relations and the fibre saturation point. New Phytol 168:25-37

Berthold J, Desbrières J, Rinaudo M, Salmén L (1994) Types of adsorbed water in relation to the ionic groups and their counterions for some cellulose derivatives. Polymer 35:5729-5736

Berthold J, Rinaudo M, Salmén L (1996) Association of water to polar groups-estimations by an adsorption model for ligno-cellulosic materials. Colloid Surf A 112:117-129

Berthold J, Olsson RJO, Salmén L (1998) Water sorption to hydroxyl and carboxylic acid groups in carboxymethylcellulose (CMC) studied with NIR-spectroscopy. Cellulose 5:281-298

Boquet R, Chirife J, Igelesias HA (1980) On the equivalence of isotherm equations. J Food Technol 15:345-349

Brunauer S (1943) The adsorption of gases and vapors-1. Physical adsorption. Princeton University Press, Princeton, p 500

Brunauer S, Emmett PH, Teller E (1938) Adsorption of gases in multimolecular layers. J Am Chem Soc 60:309-319

Çarçabal P, Jockusch RA, Hünig I, Snoek LC, Kroemer RT, Davis BG, Gamblin DP, Compagnon I, Oomens J, Simons JP (2005) Hydrogen bonding and cooperativity in isolated and hydrated sugars: mannose, galactose, glucose, and lactose. J Am Chem Soc 127:11414-11425 
Chauhan SS, Aggarwal P (2004) Effect of moisture sorption state on transverse dimensional changes in wood. Holz Roh Werkst 62:50-55

Chen CM, Wangaard FF (1968) Wettability and the hysteresis effect in the sorption of water vapour by wood. Wood Sci Technol 2:177

Chiu CM, Lin CJ (2007) Radial distribution patterns of the green moisture content in trunks of 46-yearold red cypress (Chamaecyparis formosensis). J Wood Sci 53:374-380

Christensen GN (1959) The rate of sorption of water vapour by wood and pulp. Appita J 13:112-123

Christensen GN (1965) The rate of sorption of water vapor by thin materials. In: Winn PN (ed) Volume Four: principles and methods of measuring moisture in liquids and solids. Reinhold, New York, pp 279-293

Christensen GN (1967) Sorption and swelling within wood cell walls. Nature 213:782-784

Christensen GN, Hergt HFA (1969) Effect of previous history on kinetics of sorption by wood cell walls. J Polym Sci Polym Chem 7:2427-2430

Christensen GN, Kelsey KE (1959) The rate of sorption of water vapor by wood. Holz Roh Werkst 17:178-188

Comstock GL (1963) Moisture diffusion coefficients in wood as calculated from adsorption, desorption, and steady state data. For Prod J 13:97-103

Cox J, McDonald PJ, Gardiner BA (2010) A study of water exchange in wood by means of 2D NMR relaxation correlation and exchange. Holzforschung 64:259-266

Crank J (1953) A theoretical investigation of the influence of molecular relaxation and internal stress on diffusion in polymers. J Polym Sci 11:151-168

Dent RW (1977) Multilayer theory for gas sorption-1. Sorption of a single gas. Text Res J 47:145-152

Derome D, Griffa M, Koebel M, Carmeliet J (2011) Hysteretic swelling of wood at cellular scale probed by phase-contrast X-ray tomography. J Struct Biol 173:180-190

Djolani B (1972) Hysteresis and second order effects of the moisture sorption in the wood at temperatures of 5, 21, 35 and 50 Celsius. Ann Sci Forest 29:465-474

Downes JG, Mackay BH (1958) Sorption kinetics of water vapor in wool fibers. J Polym Sci 28:45-67

Eitelberger J, Svensson S, Hofstetter K (2011) Theory of transport processes in wood below the fiber saturation point-physical background on the microscale and its macroscopic description. Holzforschung 65:337-342

Engelund ET (2011) Wood-water interactions. Dissertation, Technical University of Denmark, Kgs. Lyngby

Engelund ET, Svensson S (2011) Modelling time-dependent mechanical behaviour of softwood using deformation kinetics. Holzforschung 65:231-237

Engelund ET, Thygesen LG, Hoffmeyer P (2010) Water sorption in wood and modified wood at high values of relative humidity-part 2. Theoretical assessment of the amount of capillary water in wood microvoids. Holzforschung 64:325-330

Everett DH (1955) A general approach to hysteresis-IV. An alternative formulation of the domain model. Trans Faraday Soc 51:1551-1557

Fahlén J, Salmén L (2005) Pore and matrix distribution in the fiber wall revealed by atomic force microscopy and image analysis. Biomacromolecules 6:433-438

Forest Products Laboratory (2010) Wood handbook-wood as an engineering material, Centennial edition. Tech. Rep. FPL-GTR-190. US Department of Agriculture, Forest Service, Forest Products Laboratory. Madison

Frandsen HL (2007) Selected constitutive models for simulating the hygromechanical response of wood. Dissertation, Aalborg University, Denmark

Frandsen HL, Damkilde L, Svensson S (2007) A revised multi-Fickian moisture transport model to describe non-Fickian effects in wood. Holzforschung 61:563-572

Fringant C, Desbrières J, Milas M, Rinaudo M, Joly C, Escoubes M (1996) Characterisation of sorbed water molecules on neutral and ionic polysaccharides. Int J Biol Macromol 18:281-286

Gamstedt EK, Bader TK, de Borst K (2012) Mixed numerical-experimental methods in wood micromechanics. Unpublished review of COST FP0802

Griffin DM (1977) Water potential and wood-decay fungi. Annu Rev Phytopathol 15:319-329

Grossman PUA (1976) Requirements for a model that exhibits mechano-sorptive behaviour. Wood Sci Technol 10:163-168

Hailwood AJ, Horrobin S (1946) Absorption of water by polymers-analysis in terms of a simple model. Trans Faraday Soc 42B:84-102 
Hanhijärvi A, Hunt D (1998) Experimental indication of interaction between viscoelastic and mechanosorptive creep. Wood Sci Technol 32:57-70

Hansen KK, Lund HB (1990) Cup method for determination of water vapour transmission properties of building materials-sources of uncertainty in the method. In: Proceedings of 2nd symposium on building physics in the Nordic countries, Trondheim, Norway, pp 291-298

Hansen EW, Tangstad E, Myrvold E, Myrstad T (1997) Pore structure characterization of mesoporous/ microporous materials by H-1 NMR using water as a probe molecule. J Phys Chem B 101:10709-10714

Hansen EW, Fonnum G, Weng E (2005) Pore morphology of porous polymer particles probed by NMR relaxometry and NMR cryoporometry. J Phys Chem B 109:24295-24303

Hartley ID, Avramidis S (1993) Analysis of the wood sorption isotherm using clustering theory. Holzforschung 47:163-167

Hartley ID, Avramidis S (1996) Static dimensional changes of sitka spruce and western hemlock influenced by sorption conditions. J Inst Wood Sci 14:83-88

Hartley ID, Kamke FA, Peemoeller H (1992) Cluster theory for water sorption in wood. Wood Sci Technol 26:83-99

Hernández RE (1993) Influence of moisture sorption history on the swelling of sugar maple wood and some tropical hardwoods. Wood Sci Technol 27:337-345

Hernández RE, Bizoň M (1994) Changes in shrinkage and tangential compression strength of sugar maple below and above the fiber saturation point. Wood Fiber Sci 26:360-369

Hernández RE, Pontin N (2006) Shrinkage of three tropical hardwoods below and above the fiber saturation point. Wood Fiber Sci 38:474-483

Hill CAS, Jones D (1999) Dimensional changes in Corsican pine sapwood due to chemical modification with linear chain anhydrides. Holzforschung 53:267-271

Hill CAS, Forster SC, Farahani MRM, Hale MDC, Ormondroyd GA, Williams GR (2005) An investigation of the cell wall micropore blocking as a possible mechanism for the decay resistance of anhydride modified wood. Int Biodeterior Biodegrad 55:69-76

Hill CAS, Norton A, Newman G (2010) The water vapour sorption properties of sitka spruce determined using a dynamic vapour sorption apparatus. Wood Sci Technol 44:497-514

Hill CAS, Keating BA, Jalaludin Z, Mahrdt E (2012) A rheological description of the water vapour sorption kinetics behaviour of wood invoking a model using a canonical assembly of Kelvin-Voigt elements and a possible link with sorption hysteresis. Holzforschung 66:35-47

Hoffmeyer P, Engelund ET, Thygesen LG (2011) Equilibrium moisture content (EMC) in norway spruce during the first and second desorptions. Holzforschung 65:875-882

Hofstetter K, Hinterstoisser B, Salmén L (2006) Moisture uptake in native cellulose-the roles of different hydrogen bonds: a dynamic FT-IR study using deuterium exchange. Cellulose 13:131-145

Hozjan T, Svensson S (2011) Theoretical analysis of moisture transport in wood as an open porous hygroscopic material. Holzforschung 65:97-102

Hui CY, Wu KC, Lasky RC, Kramer EJ (1987) Case-II diffusion in polymers-1. Transient swelling. J Appl Phys 61:5129-5136

Hunt DG, Gril J (1996) Evidence of a physical ageing phenomenon in wood. J Mater Sci Lett 15:80-82

Hunt DG, Shelton CF (1988) Longitudinal moisture-shrinkage coefficients of softwood at the mechanosorptive creep limit. Wood Sci Technol 22:199-210

Irvine GM (1984) The glass transitions of lignin and hemicellulose and their measurement by differential thermal analysis. Tappi J 67:118-121

Joly C, Gauthier R, Escoubes M (1996) Partial masking of cellulosic fiber hydrophilicity for composite applications-water sorption by chemically modified fibers. J Appl Polym Sci 61:57-69

Kelley SS, Rials TG, Glasser WG (1987) Relaxation behavior of the amorphous components of wood. J Mater Sci Lett 22:617-624

Kelly MW, Hart CA (1970) Water vapor sorption rates by wood cell walls. Wood Fiber Sci 1:270-282

Kelsey KE (1957) The sorption of water vapour by wood. Aust J Appl Sci 8:42-54

Kollmann F (1962) Eine gleichung der sorptionsisotherme. Naturwissenschaften 49:206-207

Kollmann FFP, Côté WA (1968) Principles of wood science and technology: solid wood. Springer Verlag, Berlin, p 592

Krabbenhøft K, Damkilde L (2004) A model for non-Fickian moisture transfer in wood. Mater Struct 37:615-622

Landry MR (2005) Thermoporometry by differential scanning calorimetry: experimental considerations and applications. Thermochim Acta 433:27-50 
Long FA, Richman D (1960) Concentration gradients for diffusion of vapors in glassy polymers and their relation to time dependent diffusion phenomena. J Am Chem Soc 82:513-519

Lotfy M, El-osta M, Wellwood RW (1972) Short-term creep as related to microfibril angle. Wood Fiber Sci 4:26-32

Ma Q, Rudolph V (2006) Dimensional change behaviour of Carribean pine using an environmental scanning electron microscope. Dry Technol 24:1397-1403

Maréchal Y, Chanzy H (2000) The hydrogen bond network in I $\beta$ cellulose as observed by infrared spectrometry. J Mol Struct 523:183-196

Matthews JF, Skopec CE, Mason PE, Zuccato P, Torget RW, Sugiyama J, Himmel ME, Brady JW (2006) Computer simulation studies of microcrystalline cellulose I $\beta$. Carbohydr Res 341:138-152

Mauze GR, Stern SA (1984) The dual-mode solution of vinyl chloride monomer in poly(vinyl chloride). J Membr Sci 18:99-109

Murata K, Masuda M (2006) Microscopic observation of transverse swelling of latewood tracheid: effect of macroscopic/mesoscopic structure. J Wood Sci 52:283-289

Nakamura K, Hatakeyama T, Hatakeyama H (1981) Studies on bound water of cellulose by differential scanning calorimetry. Text Res J 51:607-613

Newns AC (1956) The sorption and desorption kinetics of water in a regenerated cellulose. Trans Faraday Soc 52:1533-1545

O’Sullivan A (1997) Cellulose: the structure slowly unravels. Cellulose 4:173-207

Olsson AM, Salmén L (2001) Molecular mechanisms involved in creep phenomena of paper. J Appl Polym Sci 79:1590-1595

Olsson AM, Salmén L (2004) The softening behavior of hemicelluloses related to moisture. ACS Symp Ser 864:184-197

Pallardy SG, Kozlowski TT (2008) p. 67 in Physiology of woody plants, 3rd edn. Elsevier, p 454

Peralta PN (1995) Modelling wood moisture sorption hysteresis using independent domain theory. Wood Fiber Sci 27:250-257

Peralta PN (1996) Moisture sorption hysteresis and the independent-domain theory-the moisture distribution function. Wood Fiber Sci 28:406-410

Péroval C, Debeaufort F, Despré D, Voilley A (2002) Edible arabinoxylan-based films-1. Effects of lipid type on water vapor permeability, film structure, and other physical characteristics. J Agric Food Chem 50:3977-3983

Petrov OV, Furo I (2009) NMR cryoporometry: principles, applications and potential. Prog Nucl Magn Reson Spectrosc 54:97-122

Reid ID (1995) Biodegradation of lignin. Can J Bot 73:S1011-S1018

Rouquerol F, Rouquerol J, Sing K (1999) Adsorption by powders and porous solids. Academic Press, London, p 467

Sadoh T, Christensen GN (1964) Rate of sorption of water vapour by hemicellulose. Aust J Appl Sci 15:297-308

Sakakibara A (1980) A structural model of softwood lignin. Wood Sci Technol 14:89-100

Salmén L, Fahlén J (2006) Reflections on the ultrastructure of softwood fibers. Cell Chem Technol 40:181-185

Schirmer R (1938) Die Diffusionszahl von Wasserdampf-Luftgemischen und die Verdampfungsgeschwindigkeit. VDI Beiheft Verfahrenstech 6:170

Seborg CO, Stamm AJ (1931) Sorption of water vapour by paper-making materials-1. Effect of beating. Ind Eng Chem 23:1271-1275

Seifert J (1972) Sorption and swelling of wood and wood base materials-2. Swelling behavior of wood and wood base materials. Holz Roh Werkst 30:294-303

Sheppard SE (1933) The structure of xerogels of cellulose and derivatives. Trans Faraday Soc 29:0077-0085

Simpson WT (1973) Predicting equilibrium moisture content of wood by mathematical models. Wood Fiber Sci 5:41-49

Simpson W (1980) Sorption theories applied to wood. Wood Fiber 12:183-195

Sjöström E (1993) Wood chemistry_fundamentals and applications, 2nd edn. Academic Press, San Diego, p 293

Skaar C (1984) Wood water relationships. Adv Chem Ser 207:127-172

Skaar C (1988) Wood-water relations. Springer, Berlin, p 283

Sonderegger W, Hering S, Niemz P (2011) Thermal behaviour of Norway spruce and European beech in and between the principal anatomical directions. Holzforschung 65:369-375 
Spalt HA (1958) The fundamentals of water sorption by wood. For Prod J 8:288-295

Stamm AJ (1929) The fiber-saturation point of wood as obtained from electrical conductivity measurements. Ind Eng Chem 1(2):94-97

Stamm AJ (1950) Bound water and hydration. Tappi 33:435-439

Stamm AJ (1956) Diffusion of water into uncoated cellophane from steady-state diffusion measurements. J Phys Chem 60:83-86

Stamm AJ (1959) Bound water diffusion into wood in the fiber direction. For Prod J 9:27-32

Stamm AJ (1960) Combined bound-water and water vapor diffusion into sitka spruce. For Prod J 10:644-648

Stamm AJ (1971) A review of nine methods for determining the fiber saturation points of wood and wood products. Wood Sci 4:114-128

Stamm AJ, Woodruff SA (1941) A convenient six-tube vapour sorption apparatus. Ind Eng Chem 13:0836-0838

Stevens V, Kühne G, Wienhaus O (1983) Untersuchungen zum thermoplastischen Verhalten von Ligninen. Wiss Z Techn Univ Dresden 32:149-154

Stone JE, Scallan AM (1967) Effect of component removal upon porous structure of cell wall of wood2. Swelling in water and fiber saturation point. Tappi 50:496-501

Thygesen LG, Elder T (2008) Moisture in untreated, acetylated, and furfurylated Norway spruce studied during drying using time domain NMR. Wood Fiber Sci 40:309-320

Thygesen LG, Engelund ET, Hoffmeyer P (2010) Water sorption in wood and modified wood at high values of relative humidity-Part 1: results for untreated, acetylated, and furfurylated Norway spruce. Holzforschung 64:315-323

Tiemann HD (1906) Effect of moisture on the strength and stiffness of wood. USDA Forest Service, Bulletin 70

Toba K, Yamamoto H, Yoshida M (2012) Mechanical interaction between cellulose microfibrils and matrix substances in wood cell walls induced by repeated wet-and-dry treatment. Cellulose 19:1405-1412

Van den Berg C, Bruin S (1981) Water activity and its estimation in food systems: theoretical aspects. In: Rockland LB, Stewart GF (eds) Water activity-influences on food quality. Academic Press, New York, pp 1-64

Venkateswaran A (1970) Sorption of aqueous and nonaqueous media by wood and cellulose. Chem Rev 70:619-637

Vrentas JS, Vrentas CM (1991) Sorption in glassy polymers. Macromolecules 24:2404-2412

Vrentas JS, Vrentas CM (1996) Hysteresis effects for sorption in glassy polymers. Macromolecules 29:4391-4396

Weichert L (1963) Investigations on sorption and swelling of spruce, beech and compressed beech wood at temperatures between $20 \mathrm{C}$ and $100 \mathrm{C}$. Holz Roh Werkst 21:290-300

Xie YJ, Hill CAS, Jalaludin Z, Curling SF, Anandjiwala RD, Norton AJ, Newman G (2011) The dynamic water vapour sorption behaviour of natural fibres and kinetic analysis using the parallel exponential kinetics model. J Mater Sci 46:479-489

Zabler S, Paris O, Burgert I, Fratzl P (2010) Moisture changes in the plant cell wall force cellulose crystallites to deform. J Struct Biol 171:133-141

Zelinka SL, Lambrecht MJ, Glass SV, Wiedenhoeft AC, Yelle DJ (2012) Examination of water phase transitions in Loblolly pine and cell wall components by differential scanning calorimetry. Thermochim Acta 533:39-45 